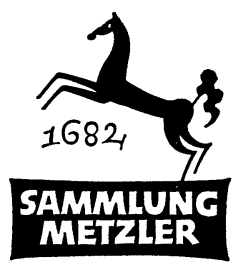

REALIENBÜCHER FÜR GERMANISTEN ABT. E: POETIK 


\section{Stoff-, Motiv-}

und

\section{Symbolforschung}

3., durchgesebene und ergänzte Auflage

\section{MCMLXX}

J.B.METZLERSCHE VERLAGSBUCHHANDLUNG 
r. Aufl. ( I.- 5. Tsd) ${ }_{96} 63$

2. Aufl. ( 6.-Io. Tsd) I 966

3. Aufl. (I I. -I 5. Tsd) I 970

M 28

ISBN 978-3-476-14028-9

ISBN 978-3-476-04129-6 (eBook)

DOI 10.1007/978-3-476-04129-6

(C) Springer-Verlag GmbH Deutschland 1963

Ursprünglich erschienen bei J. B. Metzlersche Verlagsbuchhandlung und Carl Ernst Poeschel Verlag GmbH in Stuttgart 1963 


\section{INHALT}

Herkunft und Geschichte der Begriffe Stoff, Motiv, SYMBOL . . . . . . . . . . . . . . . . . .

ENTWiCKLUNG DES ForsChUNGSGebIETES . . . . . . . . 3

Stoff-und Motivgescbicbte . . . . . . . . . . . . . . . 3

Literarkritische Ansätze - Volksliteraturforschung . . . . 3

Die Scherer-Schule - Diltheys Motivenlehre und die vergleichende Literaturwissenschaft . . . . . . . . . . . s

Abwertung der Stoff- und Motivgeschichte durch die geistesgeschichtliche Methode . . . . . . . . . . 7

Neuorientierung der Stoff- und Motivgeschichte in der modernen Poetik. . . . . . . . . . . . . 9

Symbolforschung. . . . . . . . . . . . . . I3

Christliche Symbolkunde - Romantische Mythusforschung - Philosophische Ausweitung des Begriffs Symbol . . . . . Die Literatur des Symbolismus - Symboldeutung der Psychoanalyse . . . . . . . . . . . . . . I6

Literaturwissenschaftliche Symbolforschung. . . . . . I9

Systematische Klärung der Begriffe und ihre AbgrenZUNG GEGEN VERWANDTE UND BENACHBARTE BEGRIFFE

Stoff .................... . 23

Motiv. .................... 28

Symbol ................... . . 35

MöglichkeIten UND bisherige ERgebnisse der Stoff-, Motiv- und SyMbolforschUNG . . . . . . . . . . 47

Das Verbältnis des Dichters zu Stoff, Motiv, Symbol . . . . . 48

Topik - Motivkonstanz - Routinemäßige Motivübernahme und Absinken von Motiven . . . . . . . . . 50 
Stoffübernahme und Stoff veränderung ........ $\$ 4$

Prävalenz bestimmter Motive und Symbole bei einzelnen Autoren .............. . 60

Beziebungen zwischen Nationalliteratur und Stoff, Motiv, Symbol ${ }_{7}$

Geistes- und sozialgeschicbtliche Perspektiven des Forscbungszweiges 69

Die Einheit der literarischen Generationen und Epochen 70 Stoffwandlungen und Motivmutation . . . . . . . . 73

Traditionelle, erhellende und hermetische Symbole . . . $7_{78}$

Ergiebigkeit des Forscbungszweiges für Zuweisungs-, Herkunfts- und Datierungsfragen . . . . . . . . . . . . 82

Leistungen der Stoff-, Motiv- und Symbolforschung für die Poetik . . 83

Gattungsaffinität und innere Struktur von Stoffen und Motiven. . . . . . . . . . . . . . . . . 84

Strukturveränderung bei Gattungswechsel . . . . . . . 92

Wachstum und Wahlverwandtschaft von Stoffen und Motiven. . . . . . . . . . . . . . . 95

Struktur und Funktion von Symbolen . . . . . . . . . 98

Symboldeutung .............. I02

REGISTER . . . . . . . . . . . . . . IIO 


\section{ABKÜRZUNGEN}

AfnSpr. Archiv für das Studium der neueren Sprachen und Literaturen

DLZ Deutsche Literaturzeitung

DtPhil.i.A. Deutsche Philologie im Aufriß

DVjs. Deutsche Vierteljahrsschrift für Literaturwissenschaft u. Geistesgeschichte

Euph. Euphorion

GRM Germanisch-Romanische Monatsschrift

RL Reallexikon der deutschen Literaturgeschichte

ZfdA Zeitschrift für deutsches Altertum

ZfDk Zeitschrift für Deutschkunde

ZfdPh. Zeitschrift für deutsche Philologie

ZfdU Zeitschrift für den deutschen Unterricht 